\title{
Policy Response to the Recent Analysis of the Nature of Ethical Publishing Issues As Iden- tified By the Ottawa Group in Nature
}

\author{
Yosemite Sam $^{1 *}$, Kalmi Ishmail ${ }^{2}$, Elmer Fudd ${ }^{1,2}$ \\ ${ }^{1}$ KLM, Provariant Interstercis Institute, 6000 Dry Gulch Canyon, Alomogordo, NM 88011, USA \\ ${ }^{2}$ Minion, Provariant Interstercis Institute, 6000 Dry Gulch Canyon, Alomogordo, NM 88011, USA \\ * Corresponding author: Yosemite Sam, KLM, Provariant Interstercis Institute, 6000 Dry Gulch Canyon, Alomogordo, NM 88011, USA. \\ Email: lakes46@yahoo.ca \\ Received date: December 11, 2019; Accepted date: December 23, 2019; Published date: December 30, 2019 \\ Citation: Yosemite Sam, Kalmi Ishmail (2019) Policy Response to the Recent Analysis of the Nature of Ethical Publishing Issues As Identified By \\ the Ottawa Group in Nature. J Clinical Research and Reports, 1(1); DOI: 10.31579/jcrr.19/006 \\ Copyright: (C) 2019 Yosemite Sam. This is an open access article distributed under the Creative Commons Attribution License, which permits \\ unrestricted use, distribution, and reproduction in any medium, provided the original work is properly cited.
}

The recent Delphinic policy analysis published in Nature, from the Ottawa group that gathered to define predatory journals and practices, has brought new focus to bear on this enduring problem. (https://www.nature.com/articles/d41586-019-03759-y) In response, we convened a group $(\mathrm{N}=2)$ at the International House of Policy to consider how this set of definitions reflects our own experience. The resulting IHOP Statement is still being formally formulated, but preliminary findings are as follows. The undersigned claim particular knowledge of such journalistic practices because, epistemologically speaking, they are where we live.

We address the five definitions in the same sequence in which they appear in Nature:

1. Putting profit over scholarship. Clearly this is an attractive definition but we believe that ultimately it can prove misleading, implying as it does that scholarship is in some form endemic to out operations. Thing A cannot take precedence over Thing B if the latter is not at the table in the first place. We refer the Ottawa Group to the Ferengi Rules of Acquisition for a better definition of our strict rules regarding profit, including (but not limited to): Possession is eleven-tenths of the law.

2. Having false or misleading information. Again, this misses the mark, raising the philosophical conundrum of how one may be said to have false information if information is absent. This is not mere sophistry. It is a fine yet important distinction. As a second point, many journals ensure the accuracy of their information by lifting it wholesale from prior publications, preserving the precise content and hence the correct meaning.
3. Deviating from best practices. We take the philosophical analogy of travelling down a road. Neither of us who gathered at the International House of Policy, as it happens, has ever been to the American town of Lordsburg, NM, and therefore we cannot ever be said to deviate from the main street of Lordsburg. One can deviate only from a course that one has taken in the past. (One refers to the work of the late John Ford, in 1939, as the pre-eminent study of the road to Lordsburg.) Similarly, one cannot be said to deviate from a set of best practices to which one emphatically has not adhered in the first place. Any judge would make such a charge disappear faster than an IHOP original buttermilk full-stack on seniors' Tuesday.

4. Lacking transparency. This is a more serious charge, as it unfortunately contains some uncomfortable historical truths that we can not ignore. Our group has at times failed to provide full and frank information on the nature of our tomfoolery. We are working on principles of fuller transparency but cannot reveal them as they are confidential.

5. Using indiscriminate or aggrieve solicitation. This is entirely correct. Discrimination has no place in modern society, whether based on nationality, religion, colour or other prejudices. We are therefore proud to be indiscriminate and regard this as a core value.

In conclusion, we at IHOP compliment the Ottawa group on its insights, its collegiality, and its wisdom in avoiding the LRT. We look forward to refinishing our own policy document over the coming months.

The authors declare they have no financial interests in this matter. 